\title{
Impact of Distribution Network Reconfiguration and Optimal Capacitor Placement under Wheeling Transactions
}

\author{
Telugu Sreedhar ${ }^{1 *}$, Nemmani Venkata Ramana ${ }^{2}$ \\ ${ }^{1}$ Dept. of EEE, Jawaharlal Nehru Technological University, Kakinda, Andhra Pradesh 533003, India \\ 2 Dept. of EEE, JNTUH College of Engineering, Jagtial, Jawaharlal Nehru Technological University, Telangana 505501, India
}

Corresponding Author Email: sreedhar_telugu@yahoo.co.in

https://doi.org/10.18280/mmep.070114

Received: 15 December 2018

Accepted: 6 January 2020

\section{Keywords:}

differential search algorithm, distribution network reconfiguration, feeder reconfiguration, wheeling transactions

\begin{abstract}
Distribution Network reconfiguration (DNR) and Optimal Capacitor Placement (OCP) are well known techniques to reduce power loss and maintain stable voltage levels in Distribution network. Minimization of power loss has immense effect on cost, quality and reliability of supply. Following the present trends of power trading methods, this paper explores the necessity of reconfiguration of the network and Optimal Capacitor Placement under wheeling transaction, incorporating market dispatching considerations. Wheeling transactions will add additional loss which is taken into consideration while modelling. Distribution System Operator (DSO) plays responsible role and knows how to reconfigure the network for the optimal operation of the entire system. DSO optimizes the objective function (minimization of power loss) by satisfying constraints of all the participants that includes technical as well as commercial. By its nature, DNR or Feeder Reconfiguration (FR) and OCP are a complex multi constrained optimization problem. The chosen optimization algorithm should improve the effective operation of DSO. Differential Search Algorithm (DSA) is adapted to solve this optimization problem due to its simple structure and proven faster convergence. The proposed methodology was tested on standard IEEE 33-bus distribution system. Simulation results are presented and compared with existing popular methodologies.
\end{abstract}

\section{INTRODUCTION}

A Distribution System Operator (DSO) securely operates and develops an active distribution system comprising networks, demand, generation and other flexible distributed energy resources (DER) like Wind, Solar, and Small Hydro etc. As a neutral facilitator of an open and accessible market it will enable competitive access to markets and the optimal use of DER on distribution networks to deliver security, sustainability and affordability in the support of whole system optimization. A DSO enables customers to be both producers and consumers; enabling customer access to networks and markets, customer choice and great customer service.

In the present day deregulation environment grant of Distribution Open Access (DOA) to consumers sourcing power from Distributed Generation (DG) such as Wind, Solar, and Small Hydro makes the problem for the DSO more and more complex. The terminology "Wheeling" in deregulated power industry refers to "The use of transmission or distribution facilities of a system to transmit power of and for another entity or utilities" [1]. Wheeling, in general is the transmission of power from a seller to a buyer through the network owned by a third party. Participants of these transactions includes: Distribution Generation (DG) like solar, wind, gas etc. as sellers; usual customers are as buyers and distribution network as the third party [2].

Several electricity deregulatory acts are available in the literature. Detailed survey on Wheeling transaction and way to incorporate wheeling transactions in DOA system is reported [3]. From the literature $[4,5]$ it is understood that wheeling transactions on the basis of either bilateral or multilateral trades in DOA incorporates the several financial aspects. The optimal power that can be flow in the network at a given time depends on the distribution network [6, 7]. There are many literatures [8-14] extensive research is carried out on the application of FR for and Optimal Capacitor Placement (OCP) in distribution system for minimizing power loss, maximize voltage stability and improve voltage profile. To solve multi-objective optimization problems the algorithms like MOPSO algorithm for power dispatch, machine learning algorithm based static VAR compensator to enhance voltage stability, partitioning differential transform method for solving nonlinear integrodifferential equations and integration of DG system with PV module to grid with modelling are reported [15-18].

Effective methodologies are proposed to incorporate FR and OCP in distribution network under deregulated environment. FR in distribution systems is realized the status of sectionalizing switches, for improving network performance. This involves the use of either deterministic or stochastic optimization algorithms [19-23].

The problem of FR and OCP is a complex multiconstrained optimization problem. There are several optimization algorithms proposed in the literature for optimal reconfiguration of distribution system and capacitor 
placement for power loss reduction, they are ant colony algorithm, improved binary particle swarm optimization, genetic algorithms and for optimum power flow benders decomposition is used for radial system [24-29]. To solve this complex multi- constrained optimization problem this paper proposes a new optimization algorithm -Differential Search Algorithm (DSA). The DSA is a population based meta-heuristic optimization algorithm. DSA has a simple structure that enables it to easily adapt to different numerical optimization problems. The DSA in transforming the geocentric Cartesian coordinates into geodetic coordinates is higher than those of all classical methods. For the problems of highly non linear and multi modal nature, it has been proved that DSA works well when compared to various recent optimization algorithms [30]. The proposed DSA algorithm for FR and OCP in distribution network is tested on IEEE 33 bus radial distribution network as a case study. Results are compared with that of the existing ones as reported in the literatures. Matpower is a software package is used for simulation [31]. From the above mentioned literature it is under stood that the DNR and OCP are extensively used for many power distribution network problems but fails to investigate wheeling transactions under deregulation. Hence it is essential to DSO to know the impact of DNR and OCP under wheeling transactions.

The remaining of the paper is organized as follows: Section 2 deals with mathematical modelling of Distribution Network Reconfiguration and Optimal Capacitor Placement under wheeling transactions. Section 3 presents a brief procedure of DSA algorithm and its implementation for the proposed problem is explained in Section 4. Simulation results for DNR under wheeling transactions on IEEE 33 bus radial distribution system is presented in Section 5 and Section 6 draws the conclusions.

\section{MODELLING OF NETWORK}

Modelling of distribution network system is required for implementation of wheeling transactions to this power trading problem. If an DG at bus ' $\mathrm{i}$ ' is willing to supply a load at bus ' $\mathrm{j}$ ' then a new model of distribution network is needed to carry out this wheeling transaction WT(i-j). DSO has to reconfigure the network and place the capacitor at optimal location in the network in such a way that the overall losses are to be minimum when compared to the case without reconfiguration and optimal placement of capacitor under wheeling transactions. This change in the network enhances the routine performance of DSO. To study the impact of FR and OCP in distribution network to know the overall losses are minimum, there are a three possible scenario arises which are formulated as three case studies as given below:

Case 1: DNR and OCP of Base case network (without wheeling transaction) for loss minimization

Case 2: With Case 1 optimal network, perform wheeling transaction and calculate losses. The additional loss (if any) occurred when compared to Case 1, should be supplied by the seller.

Case 3: DNR and OCP of Base case network (with wheeling transaction) for loss minimization

Hence, in all three cases the objective function to be minimized is the distribution loss present in the network. It can be mathematically given as below

$$
\min (P L O S S)=\min \left(\operatorname{real}\left[\sum_{k=1}^{N L}\left(S_{k, i j}+S_{k, j i}\right)\right]\right)
$$

Subject to

$$
\begin{gathered}
P G i-P D i-\sum_{j=1}^{n} P L O S S i j=0 \\
Q G i-Q D i-\sum_{j=1}^{n} Q L O S S i j=0 \\
V \min , i \leq V i \leq \operatorname{Vmax}, i \\
P G i \leq P G \max , i
\end{gathered}
$$

where, $P G i$ is the real power generation at bus ' $i$ '

$P D i$ is the real load in bus ' $i$ ' PLOSSij is the active power loss in the line $i j$ $Q G i$ is the reactive power generation at bus ' $i$ ' $Q D i$ is the reactive load in bus ' $i$ '

$Q L O S S i j$ is the reactive power loss in the line $i j$ $V i$ is the voltage at bus ' $i$ '

$V \min , i$ is the minimum and maximum voltage limits at bus ' $i$ '

$V \max , i$ is the maximum voltage limits at bus ' $i$ '

$S i j$ is the apparent power flow in the line $i j$

$S_{k, i j}$ is the complex power flowing from bus ' $\mathrm{i}$ ' to ' $\mathrm{j}$ '

$S_{k, j i}$ is the complex power flowing from bus ' $\mathrm{j}$ ' to ' $\mathrm{i}$ ' available at bus ' $i$ '

$P G \max , i$ is the maximum real power generation

$N G$ is the total number of generators

$N L$ is the total number of transmission lines

\section{DEFFERENTIAL SEARCH ALGORITHAM}

The Differential Search Algorithm (DSA) is a population based meta-heuristic optimization algorithm which simulates the Brownian-like random-walk movement used by an organism to migrate from one place to another based on climatic changes. During these climatic changes these organisms migrate from an environment where the available sources of nature are limited, to an environment which is rich in sources. In the migration movement, the migrating species of living beings constitute a superorganism containing a large number of individuals. Then it starts to change its position by moving towards more fruitful areas using a Brownian-like random-walk model. The population made up of random solutions of the respective problem corresponds to an artificial superorganism migrating. The artificial superorganism migrates to a near global minimum value of the problem. During this migration, artificial superorganism tests whether some randomly selected positions are suitable the temporarily during the migration. If such a position tested is suitable to stopover for a temporary time during the migration, the members of the artificial super organism that made such discovery immediately settle at the discovered position and continue the migration from this position on. Detailed explanation and pseudo-code of DSA are discussed by Civicioglu [30]. 


\section{DSA FOR DNR AND OCP UNDER WHEELING TRANSACTIONS}

In the problem of DNR the loss minimization is obtained by optimally selecting switches which are to be closed and opened. When a tie switch is closed a loop is formed, therefore another switch in that loop should be opened to ensure radial structure. For this reason first, a Switch_Information_Matrix (SIM) is formulated which contains the information of the sectionalizing and or tie switches to be opened when a corresponding tie switch is closed. This depends on the number of loops created. The row size of SIM depends upon the number of tie switches whereas the size of column depends on the number of switches present in that loop. In case of OCP, optimal values of capacitors from standard set of practically available ranges must be chosen and located at buses optimally so that the overall loss is minimized as well as maintaining voltage profile within the limits. Hence the DSA should simultaneously select a suitable switch number from the SIM matrix for DNR and optimal capacitor value and suitable location for placing it. A description about the implementation of DSA for DNR and OCP problem is given below.

\subsection{Implementation of DSA for DNR under Wheeling Transactions}

The problem is initialized as given below

$$
\begin{aligned}
& \mathrm{X}_{\min }=\left[\begin{array}{llll}
1 & 1 \ldots . .1, & 1 \ldots \ldots .1 & 1 \ldots \ldots . .1
\end{array}\right] \\
& \mathrm{X}_{\max }=[\mathrm{Lm} 1 \mathrm{Lm} 2 \mathrm{LmD}, \mathrm{Lcb} 1 . . \mathrm{LcbN} \operatorname{Lcs} 1 . . \mathrm{LcsN}]
\end{aligned}
$$

where, 'Lm' refers to the maximum number of lines in each loop, ' $\mathrm{D}$ ' is the dimension vector or number of tie switches, 'Lcb' refers to capacitor buses, 'Lcs' refers to the sizing of capacitors, ' $\mathrm{N}$ ' is the maximum number of capacitors and ' $\mathrm{X}$ ' is the artificial organism. Assuming a total population of 'NP', then we may initialize the $\mathrm{j}^{\text {th }}$ component of $\mathrm{i}^{\text {th }}$ vector (assuming $i=1,2,3, \ldots . . \mathrm{NP}$ ) as

$$
x_{i j}=\operatorname{rand}\left(\mathrm{X}_{\max }-\mathrm{X}_{\min }\right)+\mathrm{X}_{\min \mathrm{j}}=1,2,
$$

thus forming the artificial organism

$$
\mathrm{X}_{\mathrm{i}}=[\mathrm{xi1}, \mathrm{xi2}, \mathrm{xi3}, \ldots . . \mathrm{xiD}+\mathrm{N}]
$$

Each artificial organism corresponds to chromosomes of Genetic Algorithm (GA), onthe other hand the population set of DSA refers to Super organisms i.e.

Superorganism $_{g}=\left[\mathrm{X}_{\mathrm{i}}\right] \mathrm{g}$ where $g=1, \ldots, \mathrm{NG}$ (number of maximum generations). Randomly, the Superorganism $g$ is shuffled to form donors in order to discover the stopover site. A stopover site (vectors- $\mathrm{Xs}$ ) at the areas remaining between the artificial organisms using a Brownian-like random walk model are determined using

$$
\begin{gathered}
\text { Stopoversite }_{g}=\text { Superorganism }_{g}+\text { Scale } \times(\text { donor }- \\
\text { Superorganism } \left._{g}\right)
\end{gathered}
$$

The Scale value is produced using a gamma-random number generator which allows the respective artificial Superorganism to radically change its direction in the habitat. Then using a random search process as shown by Civicioglu [30] an update in Stopoversite is made. The selection of new artificial Superorganism $g+1$ is chosen between the existing Stopoversite and the Superorganism $g$ as given below

$$
\begin{gathered}
{\left[\mathrm{X}_{\mathrm{i}}\right]_{\mathrm{g}+1}=\left[\mathrm{Xs}_{\mathrm{i}}\right] \mathrm{g} \text { if } \mathrm{f}\left(\left[\mathrm{Xs}_{\mathrm{i}}\right] \mathrm{g}\right) \leq \mathrm{f}\left(\left[\mathrm{X}_{\mathrm{i}}\right] \mathrm{g}\right)} \\
=\left[\mathrm{X}_{\mathrm{i}}\right] \mathrm{g} \text { if } \mathrm{f}\left(\left[\mathrm{Xs}_{\mathrm{i}}\right] \mathrm{g}\right) \geq \mathrm{f}\left(\left[\mathrm{X}_{\mathrm{i}}\right] \mathrm{g}\right)
\end{gathered}
$$

\subsection{Algorithm of DNR and OCP for Wheeling transaction using DSA problem}

The step by step algorithm of DNR and OCP for wheeling transaction using DSA is as follows:

Step 1: Read feeder data, line data, Capacitor ratings, wheeling transaction seller bus (DG sizing) and buyer bus (load demand), size of population, number of tie switches etc.

Step 2: For Case 1: The DSA algorithm (sec.4.1) is used to find the optimal reconfigured network and optimal sizing and placement of capacitors with minimum loss for base case.

Step 3: For Case2: Establish the wheeling transaction in the optimal network of Case 1. i.e. connect the generator at seller bus and increase the load at buyer bus while keeping the feeder generations at optimal values obtained in Case 1. Run power flow and find the loss occurred in optimal network of Case 1 under wheeling transactions.

Step 4: For Case 3: Establish the wheeling transaction in the Base case network. i.e. to connect the generator at seller bus and increase the load at buyer bus. Use DSA algorithm to find the optimal reconfigured network and optimal sizing and placement of capacitors while minimizing the losses.

Step 5: Compare the results of Case 2 and Case 3 for minimum loss which gives the impact of DNR and OCP under wheeling transactions. argue the case for the study, outlining only essential background, and should not include the findings or the conclusions. It should not be a review of the subject area, but should finish with a clear statement of the question being addressed.

\section{SIMULATION RESULTS AND DISCUSSION}

The test system chosen for studying the impact of DNR and OCP under wheeling transaction is IEEE 33 bus radial system [29]. The complete DSA coding [30] and power flow using MATPOWER [31] software is done in MATLAB 2009 b environment using INTEL core i5-2520M @ $2.5 \mathrm{GHz}$ processor, 8 GB RAM under Windows 7 professional operating system. The parameters for DSA are Number of population -30, Number of Generations - 500, trial pattern generation $\mathrm{P}=0.3 *$ random number. The number of capacitors is assumed to be 5 , and the values considered are $300,600,900,1200,1500,1800 \mathrm{Kvar}$. The simulation results for each case are as given below. 


\subsection{Case 1}

The IEEE 33 bus radial network has 32 sectional lines with 5 tie switches. Its total complex power demand is $3.72+\mathrm{j} 2.3$ MVA. Also, for the base case network (without DNR and OCP) the power loss is $202.7052 \mathrm{~kW}$. After applying DNR and OCP using DSA method the optimal network and its losses are as furnished in Table 1. It can be observed that configuration obtained by the proposed method is one of the best solutions obtained so far. The capacitors are optimally located by DSA as Bus 9 - 300 Kvar, Bus 21 - 300 Kvar, Bus 23 - 300 Kvar, Bus 25 - 300 Kvar and at Bus 30 - 900 Kvar. The percentage reduction in power loss is $54.9639 \%$. The minimum voltage is 0.9130 p.u. at bus 18 without DNR and OCP, whereas the minimum voltage with DNR and OCP using DSA is 0.9592 p.u. at bus 32. The voltage profile at all buses with and without DNR with OCP using DSA is shown in Figure 1. The convergence characteristics are shown in Figure 2.

Table 1. Comparison of simulation results with and without DNR and OCP using DSA

\begin{tabular}{ccccc}
\hline \multirow{2}{*}{ Method } & \multicolumn{2}{c}{ Without DNR and OCP } & \multicolumn{2}{c}{ With DNR and OCP } \\
\cline { 2 - 5 } & Lines switched out & Total Loss $(\mathbf{k W})$ & Lines switched out & Total Loss (kW) \\
\hline Reference ACO [24] & $33-34-35-36-37$ & 202.705 & $7-9-14-32-37$ & 95.79 \\
\hline Reference iBPSO [25] & $33-34-35-36-37$ & 202.705 & $7-9-14-32-37$ & 93.061 \\
\hline DSA (proposed) & $\mathbf{3 3 - 3 4 - 3 5 - 3 6 - 3 7}$ & $\mathbf{2 0 2 . 7 0 5}$ & $7-9-14-32-37$ & $\mathbf{9 1 . 9 1 8}$ \\
\hline
\end{tabular}

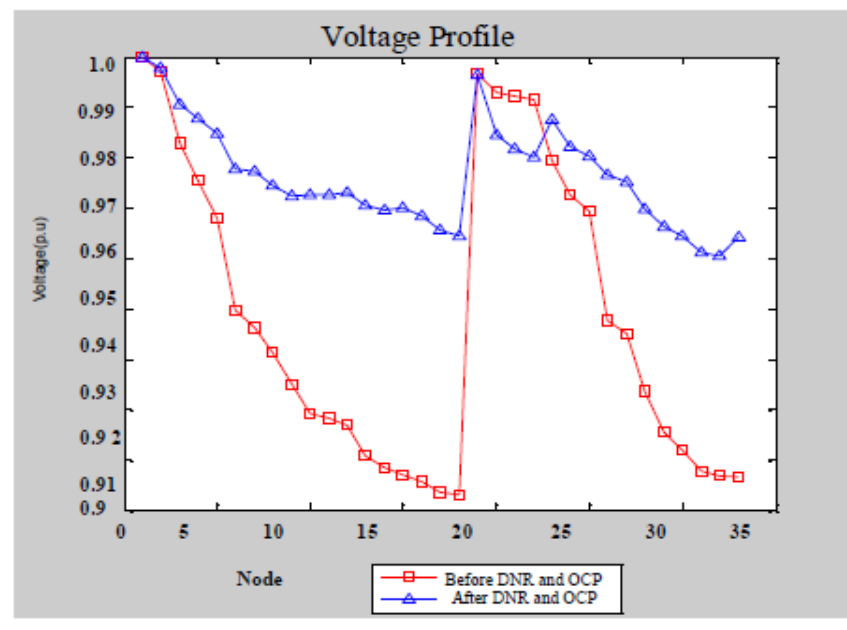

Figure 1. Case 1 - Voltage profile

\subsection{Case 2}

As a case study let us assume the data for generator and load for wheeling transactions as given in Table 2. For case 2, the above mentioned wheeling transaction is established in the optimal network obtained in Case 1, i.e with lines 7-9-1432-37 switched out and capacitors rating and placement as in Case 1. The observations based on load flow are furnished in

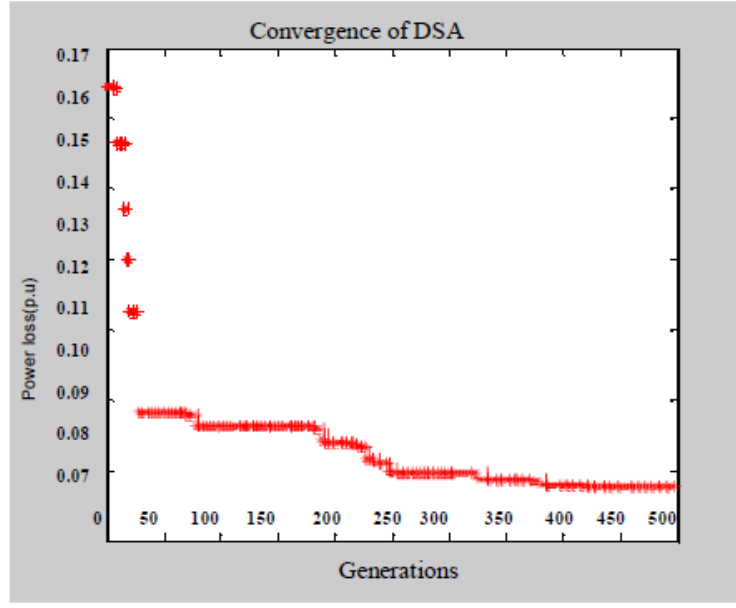

Figure 2. Case 1 - Convergence characteristics

column 2 of Table 3 . It is observed that the additional load of $100 \mathrm{~kW}$ at the buyer bus 33, increases the losses from the optimal case 1 value of $91.98 \mathrm{~kW}$ to $98.64 \mathrm{~kW}$. Hence this additional loss $6.66 \mathrm{~kW}$ loss has to be supplied by the seller. Hence the establishment of wheeling transactions in case 1 optimal network is not economically worthy either for the seller or for the distribution utility.

Table 2. Data for wheeling transaction (Bilateral)

\begin{tabular}{ccccc}
\hline Generator (Seller) & Bus 3 & Pg = 100 kW & $\begin{array}{c}\text { Pgmax= 500 kW } \\
\text { Pgmin }=0 \text { kW }\end{array}$ & $\begin{array}{c}\text { Qg = 0 kVar } \\
\text { i.e pf = unity }\end{array}$ \\
\hline Load (Buyer) & Bus33 (additional load) & $\mathrm{Pd}=100 \mathrm{~kW}$ & $\mathrm{Qd}=0 \mathrm{kVar}$ & \\
\hline
\end{tabular}

Table 3. Simulation results for Case 2 and Case 3 - Under Wheeling transaction

\begin{tabular}{ccc}
\hline Under Wheeling Transactions & Case 2 & Case 3 \\
\hline Lines switched out & $7-9-14-32-37$ & $\mathbf{7 - 9 - 1 4 - 3 2 - 3 7}$ \\
\hline & Bus 9-300 Kvar & Bus 9- 300 Kvar \\
& Bus 21- 300 Kvar & Bus 11- 300 Kvar \\
Capacitor Placement & Bus 23-300 Kvar & Bus 24- 600 Kvar \\
& Bus 25-300 Kvar & Bus 27 - 300 Kvar \\
& Bus 30-900 Kvar & Bus 30- 900 Kvar \\
\hline Minimum Voltage & 0.9532 & $\mathbf{0 . 9 5 3 3}$ \\
\hline Total loss & $98.64 \mathrm{~kW}$ & $\mathbf{9 7 . 4 9} \mathbf{~ k W}$ \\
\hline \% Reduction in loss & - & $\mathbf{1 . 1 6 4 \%}$ \\
\hline
\end{tabular}




\subsection{Case 3}

For case 3, the Table 2 data for wheeling transaction is established and the DNR with OCP using DSA is applied again to find the optimal solution. The Voltage profiles of case 2 and case 3 is shown in Figure 3. Though the lowest voltage remains the same the overall voltage profile is improved which is evident from Figure 3. The convergence characteristics for DNR and OCP using DSA are shown in Figure 4. The optimal network and the corresponding losses are furnished in column 3 of Table 3 . For this case the total loss is $97.49 \mathrm{~kW}$ which is $1.164 \%$ lesser when compared to Case 2. From Table 3 it is evident that though the reconfigured network remains the same for Case 2 and Case 3 , the optimal capacitor location and its value differs which aids in obtaining the reduction in loss and improved voltage profile. Hence the Distribution utility (DSO) has to participate in the wheeling transaction by optimally reconfiguring the network and placing capacitors at optimal locations so that the utility, seller and the buyer can benefit economically.

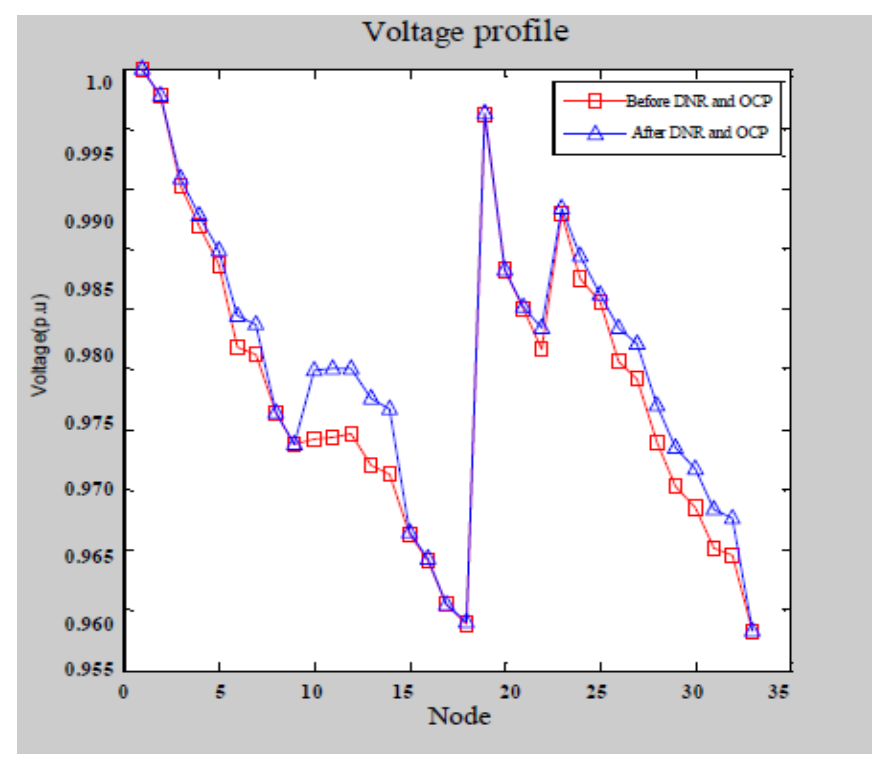

Figure 3. Case 2 and Case 3 - Voltage profile

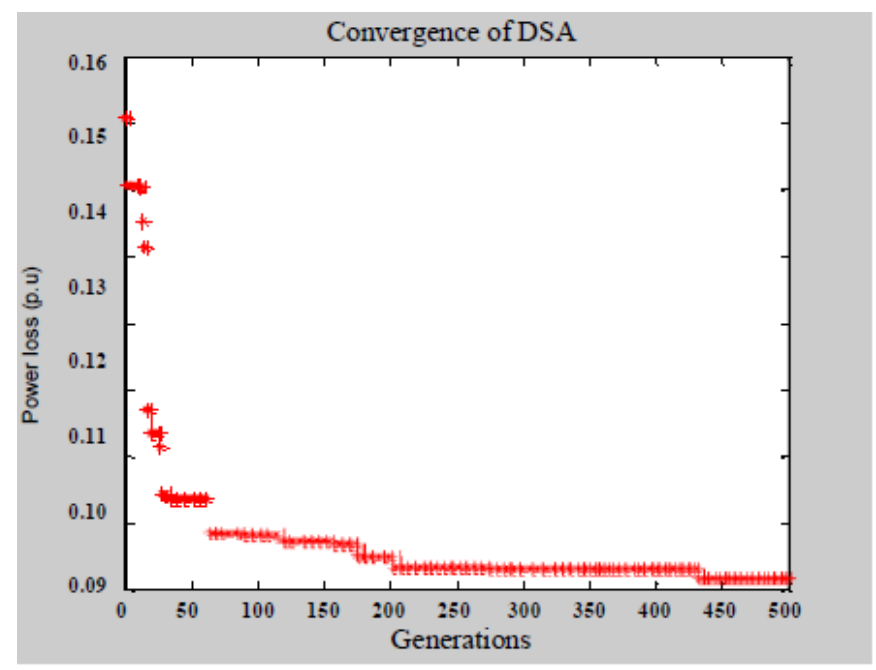

Figure 4. Case 3 - Convergence characteristics

\section{CONCLUSIONS}

This paper presented a new optimization algorithm DSA which is simple in structure and faster convergence to minimize the power loss under wheeling transaction with DNR and OCP for effective operation of distribution network by DSO. Three different case studies (Case 1 to 3 ) are considered to analyze the impact of FR and OCP under wheeling transaction, incorporating market dispatching considerations. All these cases are tested on IEEE 33-bus distribution system. From the simulation results it can be concluded that under wheeling transactions the existing network is not optimal based on loss or on Voltage profile. DSO can implement DNR and OCP as an effective operational strategy under wheeling transaction for betterment of voltage profile and loss minimization. In future this methodology may be extended duly incorporating the FACT devices in the distribution network under wheeling transactions.

\section{REFERENCES}

[1] Merrill, H.M., Erickson, B.W. (1989). Wheeling rates based on marginal-cost theory. IEEE Transactions on Power Systems, 4(4): 1445-1451 https://doi.org/10.1109/59.41696

[2] Caramanis, M.C., Bohn, R.E., Schweppe, F.C. (1986). The costs of wheeling and optimal wheeling rates. IEEE Transactions on Power Systems, 1(1): 63-73 https://doi.org/10.1109/TPWRS.1986.4334845

[3] Sood, Y.R., Padhy, N.P., Gupta, H.O. (2002). Wheeling of power under deregulated environment of power system - a bibliographical survey. IEEE Transactions on Power Systems, 17(3): 870-878 https://doi.org/10.1109/TPWRS.2002.800967

[4] Amendment to the MERC (Distribution Open Access) Regulations. (2016). Maharashtra State Electricity Distribution Co. Ltd., India. https://www.mahadiscom. $\mathrm{in} / \mathrm{msedcls-comments-on-draft-regulations-rules,}$ accessed on Jun. 8, 2019.

[5] Delhi Electricity Regulatory Commission. (2015). Proposal for determination of open access charges. http://www.derc.gov.in/ordersPetitions/orders/Tariff/Ta riff $\% 20$ Order/Archives-Others.html, accessed on Dec. 16, 2015.

[6] Khamees, A.K., Badra, N.M., Abdelaziz, AY. (2016). Optimal power flow methods: A comprehensive survey. International Electrical Engineering Journal, 7(4): 22282239.

[7] Enshaee, A., Enshaee, P. (2017). New reactive power flow tracing and loss allocation algorithm for grids using matrix calculation. Electric Power and Energy System, 87: 89-98. https://doi.org/10.1016/j.ijepes.2016.11.010

[8] Mishra, S., Das, D., Paul, S. (2017). A comprehensive review on power distribution network reconfiguration. Energy Systems, 8(2): 227-284. https://doi.org/10.1007/s12667-016-0195-7

[9] Abd El-salam, M.F., Beshr, E., Eteiba, M.B. (2018). A new hybrid technique for minimizing power losses in a distribution system by optimal sizing and siting of distributed generators with network reconfiguration. 
Energies,

11(12):

3351.

https://doi.org/10.3390/en11123351

[10] Roosta, A., Eskandari, H., Khooban, M. (2019). Optimization of radial unbalanced distribution networks in the presence of distribution generation units by network reconfiguration using harmony search algorithm. Neural Comput \& Applic, 31, 7095-7109. https://doi.org/10.1007/s00521-018-3507-0

[11] Abdelaziz, A.Y., Ali, E.S., Elazim, S.A. (2016). Optimal sizing and locations of capacitors in radial distribution systems via flower pollination optimization algorithm and power loss index. Int J Eng Sci Technol, 19(1):

610-618. https://doi.org/10.1016/j.jestch.2015.09.002

[12] Hussain, A.N., Al-Jubori, W.K.S., Kadom, H.F. (2019). Hybrid design of optimal capacitor placement and reconfiguration for performance improvement in a radial distribution system. Hindawi Journal of Engineering, 2019: 15 pages. https://doi.org/10.1155/2019/1696347

[13] Nguyen, T.T., Truong, A.V., Phung, T.A. (2016). A novel method based on adaptive cuckoo search for optimal network reconfiguration and distributed generation allocation in distribution network. International Journal of Electrical Power \& Energy Systems, 30(78): 801-815. https://doi.org/10.1016/j.ijepes.2015.12.030

[14] Namachivayam, G., Sankaralingam, C., Perumal, S.K., Devanathan, S.T. (2016). Reconfiguration and capacitor placement of radial distribution systems by modified flower pollination algorithm. Electric Power Components and Systems, 44(13): 1492-1502. https://doi.org/10.1080/15325008.2016.1172281

[15] Sen, G.D., Sharma, J., Goyal, G.R., Singh, A.K. (2017). A Multi-objective PSO (MOPSO) algorithm for optimal active power dispatch with pollution control. Mathematical Modelling of Engineering Problems, 4(3): 113-119. https://doi.org/10.18280/mmep.040301

[16] Kunamneni, R., Ramavathu, S.N. (2019). A grid connected modular multilevel converter for photovoltaic energy conversion. Mathematical Modelling of Engineering Problems, 6(4): 535-540. https://doi.org/10.18280/mmep.060408

[17] Machavarapu, S., Rao, M.V.G., Rao, P.V.R. (2019). Machine learning algorithm based static VAR compensator to enhance voltage stability of multimachine power system. Mathematical Modelling of Engineering Problems, 6(4): 641-649 https://doi.org/10.18280/mmep.060420

[18] Radid, A., Rhofir, K. (2019). Partitioning differential transformation for solving integro-differential equations problem and application to electrical circuits. Mathematical Modelling of Engineering Problems, 6(2): 235-240. https://doi.org/10.18280/ mmep.060211

[19] Mohamed, E., Mohamed, A.A.A., Mitani, Y. (2018). MSA for optimal reconfiguration and capacitor allocation in radial/ ring distribution networks. International Journal of Interactive Multimedia and Artificial Intelligence, 5(1): 107-122. https://doi.org/10.9781/ijimai.2018.05.002

[20] Diab, A.A.Z., Rezk, H. (2019). Optimal sizing and placement of capacitors in radial distribution systems based on grey wolf, dragonfly and moth-flame optimization algorithms. Iranian Journal of Science and Technology, Transactions of Electrical Engineering, 43(1): 77-96. https://doi.org/10.1007/s40998-018-00717

[21] Devabalaji, K.R., Yuvaraj, T., Ravi, K. (2018). An efficient method for solving the optimal sitting and sizing problem of capacitor banks based on cuckoo search algorithm. Ain Shams Engineering Journal, 9(4): 589-597. https://doi.org/10.1016/j.asej.2016.04.005

[22] Tamilselvan, T. Jayabarathi, Raghunathan, T., Yang, X.S. (2018). Optimal capacitor placement in radial distribution systems using flower pollination algorithm. Alexandria Engineering Journal, 57(4): 2775-2786. https://doi.org/10.1016/j.aej.2018.01.004

[23] El-Fergany, A.A. (2013). Optimal capacitor allocations using evolutionary algorithms. IET Generation, Transmission \& Distribution, 7(6): 593-601. https://doi.org/10.1049/iet-gtd.2012.0661

[24] Kasaei, M.J., Gandomkar, M. (2009). Loss reduction in distribution system with simultaneous using of capacitor placement and reconfiguration by ant colony algorithm. 24th International Power System Conference, Tehran, Iran, $\quad$ pp. 23-35. https://doi.org/10.1109/APPEEC.2010.5448826

[25] Sedighizadeh, M., Dakhem, M., Sarvi, M., Kordkheili, H.H. (2014). Optimal reconfiguration and capacitor placement for power loss reduction of distribution system using improved binary particle swarm optimization. International Journal of Energy and Environmental Engineering, Sringer Open Journal, 5(3): 1-11. https://doi.org/10.1186/2251-6832-5-3

[26] Khodr, H.M., Martinez-Crespo, J., Matos, M.A., Pereira, J. (2009). Distribution systems reconfiguration based on OPF using benders decomposition. IEEE Trans Power Delivery, 24(4): 2166-2176. https://doi.org/10.1109/TPWRD.2009.2027510

[27] de Macedo Braz, H.D., de Souza, B.A. (2011). Distribution network reconfiguration using genetic algorithms with sequential encoding: subtractive and additive approaches. IEEE Transactions on Power Systems, 26(2): 582-59. https://doi.org/10.1109/TPWRS.2010.2059051

[28] Zimmerman, R.D., Murillo-Sanchez, C.E., Thomas, R.J. (2011). MATPOWER: Steady-state operations, planning and analysis tools for power systems research and education. Power Systems, 26(1): 12-19. https://doi.org/10.1109/TPWRS.2010.2051168

[29] Venkatesh, B., Ranjan, R., Gooi, H.B. (2004). Optimal reconfiguration of radial distribution systems to maximize loadability. IEEE Trans. on Power System, 19(1): 260-266. https://doi.org/10.1109/TPWRS.2003.818739

[30] Civicioglu, P. (2012). Transforming geocentric Cartesian coordinates to geodetic coordinates by using differential search algorithm. Computers \& Geosciences, 46: 229-247. https://doi.org/10.1016/j.cageo.2011.12.011

[31] Zimmermann, R.D., Murillo-Sánchez, C.E. (2007). Matpower aMatlab® power system simulation package. User's Manual 2007, Version 3.2. https://matpower.org/download/manual.pdf, accessed on Jan. 19, 2016. 